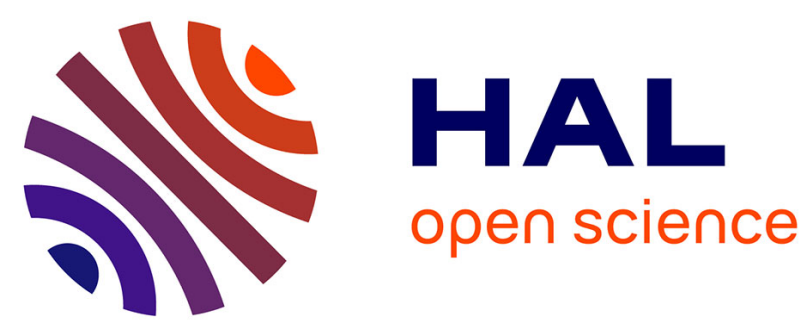

\title{
Biochemical characterization and immunogenicity of Neureight, a recombinant full-length factor VIII produced by fed-batch process in disposable bioreactors
}

Sandrine Delignat, Ivan Peyron, Maria El Ghazaly, Srinivas V. Kaveri, Jan Rohde, Frank A. Mueller, Sébastien Lacroix-Desmazes

\section{To cite this version:}

Sandrine Delignat, Ivan Peyron, Maria El Ghazaly, Srinivas V. Kaveri, Jan Rohde, et al.. Biochemical characterization and immunogenicity of Neureight, a recombinant full-length factor VIII produced by fed-batch process in disposable bioreactors. Cellular Immunology, In press, 10.1016/j.cellimm.2018.05.002 . hal-01832020

\section{HAL Id: hal-01832020 \\ https: / hal.sorbonne-universite.fr/hal-01832020}

Submitted on 6 Jul 2018

HAL is a multi-disciplinary open access archive for the deposit and dissemination of scientific research documents, whether they are published or not. The documents may come from teaching and research institutions in France or abroad, or from public or private research centers.
L'archive ouverte pluridisciplinaire HAL, est destinée au dépôt et à la diffusion de documents scientifiques de niveau recherche, publiés ou non, émanant des établissements d'enseignement et de recherche français ou étrangers, des laboratoires publics ou privés. 


\title{
Biochemical characterization and immunogenicity of Neureight, a recombinant full-length factor VIII produced by fed-batch process in disposable bioreactors
}

\author{
Sandrine Delignat ${ }^{\mathrm{a}, \mathrm{b}, \mathrm{c}}$, Ivan Peyron ${ }^{\mathrm{a}, \mathrm{b}, \mathrm{c}}$, Maria El Ghazaly ${ }^{\mathrm{d}}$, Srinivas V Kaveri ${ }^{\mathrm{a}, \mathrm{b}, \mathrm{c}}$, Jan Rohde ${ }^{\mathrm{d}}$, \\ Frank Mueller ${ }^{\mathrm{d}}$, Sebastien Lacroix-Desmazes ${ }^{\mathrm{a}, \mathrm{b}, \mathrm{c}, *}$ \\ a INSERM, UMR S 1138, Centre de Recherche des Cordeliers, Paris F-75006 France \\ ${ }^{\mathrm{b}}$ Université Pierre et Marie Curie-Paris6, UMR S 1138, Centre de Recherche des Cordeliers, Paris F-75006 France \\ ${ }^{\mathrm{c}}$ Université Paris Descartes, UMR S 1138, Centre de Recherche des Cordeliers, Paris F-75006 France \\ ${ }^{\mathrm{d}}$ Minapharm Pharmaceuticals, Cairo, Egypt
}

\begin{tabular}{|c|c|}
\hline & A B S T R A C T \\
\hline $\begin{array}{l}\text { Keywords: } \\
\text { Hemophilia A } \\
\text { Factor VIII } \\
\text { Immunogenicity } \\
\text { Disposable fed-batch production technology } \\
\text { CHO cell line }\end{array}$ & $\begin{array}{l}\text { Hemophilia A is a X-linked recessive bleeding disorder consecutive to the lack of circulating pro-coagulant factor } \\
\text { VIII (FVIII). The most efficient strategy to treat or prevent bleeding in patients with hemophilia A relies on } \\
\text { replacement therapy using exogenous FVIII. Commercially available recombinant FVIII are produced using an } \\
\text { expensive perfusion technology in stainless steel fermenters. A fed-batch fermentation technology was recently } \\
\text { developed to produce 'Neureight', a full-length recombinant human FVIII, in Chinese hamster ovary (CHO) cells. } \\
\text { Here, we investigated the structural and functional integrity and lack of increased immunogenicity of Neureight, } \\
\text { as compared to two commercially available full-length FVIII products, Helixate and Advate, produced in baby } \\
\text { hamster kidney or CHO cells, respectively. Our results demonstrate the purity, stability and functional integrity } \\
\text { of Neureight with a standard specific activity of } 4235 \pm 556 \text { IU/mg. The glycosylation and sulfation profiles of } \\
\text { Neureight were similar to that of Advate, with the absence of the antigenic carbohydrate epitopes } \alpha \text {-Gal and } \\
\text { Neu5Gc, and with sulfation of Y1680, that is critical for FVIII binding to von Willebrand factor (VWF). The } \\
\text { endocytosis of Neureight by human immature dendritic cells was inhibited by VWF, and its half-life in FVIII- } \\
\text { deficient mice was similar to that of Advate, confirming unaltered binding to VWF. In vitro and in vivo assays } \\
\text { indicated a similar immunogenicity for Neureight, Advate and Helixate. In conclusion, the production of full- } \\
\text { length FVIII in a fed-batch fermentation mode generates a product that presents similar biochemical, functional } \\
\text { and immunogenic properties as products developed using the classical perfusion technology. }\end{array}$ \\
\hline
\end{tabular}

\section{Introduction}

Hemophilia A is a X-linked recessive bleeding disorder consecutive to the lack of circulating pro-coagulant factor VIII (FVIII) [1]. Treatment and prevention of bleedings in patients with hemophilia A rely on replacement therapy using either plasma-derived or recombinant FVIII [2]. FVIII is among the most expensive protein therapeutics on the market owing to the low yields of production of the glycoprotein in the case of recombinant products and to the different steps required to eliminate potential viral agents [3]. The poor stability of FVIII [4,5] is an additional constraint that participates in increase of production costs. Production processes for recombinant FVIII (both full-length or B domain-deleted) are all based on expensive perfusion technology in stainless steel fermenters [6-8]. The use of continuous perfusion technology allows the growth of FVIII-producing cells to high concentrations while ensuring a relatively short protein residence time $[9,10]$. Shorter residence times were proposed to allow efficient production and less disruption of the recombinant FVIII (rFVIII) protein [11], thus minimizing the generation of potentially immunogenic FVIII degradation products. To address the need for better supply of affordable rFVIII at global level, efforts have focused on cell line development, process improvements and optimization of expression rates in commercial mammalian cell culture processes. Nevertheless, expression does typically not exceed $0.1 \mathrm{mg}$ FVIII/L cell culture supernatant for a full-length FVIII [12].

We recently developed a fed-batch fermentation technology based on disposable fermentation technology to produce a full-length recombinant human FVIII. Compared to perfusion technology, fed-batch

\footnotetext{
* Corresponding author at: INSERM UMR S 1138, Centre de Recherche des Cordeliers, Paris F-75006, France.

E-mail address: Sebastien.Lacroix-Desmazes@crc.jussieu.fr (S. Lacroix-Desmazes).
} 
processes have significant advantages, such as ease of process validation and characterization, better lot definition and consistency, ease of downstream processing, overall reduced time to product approval, reduced medium consumption, reduced waste generation, less manpower requirements $[9,13]$, easier technology transferability and less automation requirements. Current state-of-the-art single-use disposable technologies have been recognized as an increasing trend in biopharmaceutical manufacturing due to several advantages like reduction of the risk for cross-contamination, elimination of cleaning steps and an increase in flexibility, ease for handling and an estimated reduction in costs between 20 and 40\% [14-16]. In the present work, the new fulllength FVIII, referred to as Neureight, was compared to available fulllength recombinant products, and the immunogenicity was assessed in in vitro and in vivo assays.

\section{Material and methods}

\subsection{Sources of FVIII and VWF}

Neureight is a recombinant full-length FVIII produced in eukaryotic $\mathrm{CHO}$ cells using a fed-batch process in a disposable setting in the absence of any stabilizing agents such as of VWF or human serum albumin. The purification of Neureight involves a step of affinity chromatography using the VIIIselect matrix (GE Healthcare, Piscataway, NI, USA) followed by traditional ion exchange, a hydrophobic interaction chromatography steps and virus reduction steps such as detergent treatment and nanofiltration. Helixate and Advate were purchased from CSL-Behring (Marburg, Germany) and Shire (Vienna, Austria), respectively. For in vitro studies, the three full-length FVIII were reconstituted in their respective excipients and dialyzed against DMEM-F12 for $2 \mathrm{~h}$ at $4{ }^{\circ} \mathrm{C}$. FVIII were then aliquoted and stored at $-80^{\circ} \mathrm{C}$ until use. FVIII:Ag and FVIII:C in aliquots were assessed by Asserachrom (Stago, Asnières sur Seine, France) and by chromogenic assay (Dade-Behring, Marburg, Germany), respectively. Total protein content was measured by Bradford using bovine serum albumin as a standard. FVIII levels are indicated as International Units (IU) per $\mathrm{ml}$ based on the FVIII:Ag levels. Wilfactin (LFB, Les Ulis, France) was used a source of VWF. It was dialyzed in DMEM-F12 during $2 \mathrm{~h}$ at $4^{\circ} \mathrm{C}$, and aliquoted and stored at $-80^{\circ} \mathrm{C}$.

\subsection{Electrophoretic and Western blot analyses}

SDS-PAGE was performed using 4-12\% Bis-TrisNuPage gels (Life Technologies, Carlsbad, California, USA) followed by a staining with a Silver Express Stain Kit (Life Technologies). Western blotting was carried out using an anti-FVIII antibody GMA-012 (Green Mountain Antibodies, Burlington, VT, USA) which recognizes the A2 domain epitopes at residues $497-510$ and $584-593$, followed by an alkaline phosphatase conjugated anti-mouse antibody (Sigma-Aldrich Chemie $\mathrm{GmbH}$, Munich, Germany).

\subsection{Glycan profiling}

MALDI-TOF MS analysis of N-glycans was performed after deglycosylation and derivatization of the separated and purified N-glycans. The permethylated glycans were further purified by a C18 cartridge and lyophilized, solubilized with $50 \% \mathrm{v} / \mathrm{v}$ methanol:water and mixed with MALDI mass spectrometry matrix before analysis. Positive ion reflectron MALDI mass spectra were acquired on a VOYAGER DE PRO (AB Sciex). Relative intensities (\%) of N-glycans were determined based on the peak heights of the corresponding deisotoped monoisotopic mass ions. Interpretation of glycan structures corresponding to monoisotopic masses was performed using ExPASyGlycoMod tool and GlycoWork Bench.

\subsection{Identification and assignment of sulfation sites, glycosylation sites and glycopeptides}

Tryptic digestion and detection of the sulfo- and glycopeptides by MS and tandem MS (MS/MS) was performed to elucidate the sulfation and glycosylation sites and the corresponding glycans. The yielded tryptic glycopeptides were purified and enriched for the respective analysis by MALDI-TOF MS where positive ion linear MALDI mass spectra were acquired in different mass ranges and with multiple acquisition conditions on a MALDI-TOF/TOF Autoflex III spectrometer (Bruker Daltonics). Further, the separated glycopeptide-enriched fractions were deglycosylated, and the yielded peptides were also analyzed by MALDI-TOF MS where positive ion reflectron and linear MALDI mass spectra were acquired in different mass ranges and with multiple acquisition conditions on a MALDI-TOF/TOF Autoflex III spectrometer (Bruker Daltonics). This was done for determining which of the theoretical N-glycosylation sites are actually occupied with N-glycans.

For identification of sulfation sites, the obtained deglycosylated peptides were also injected on a nano-HPLC system coupled to an ion trap nano-electrospray mass spectrometer (LTQvelos, ThermoScientific). Acquisition of mass data was performed in a mass range of 300 to $2000 \mathrm{Da}$ excluding monocharged ions. Proteome Discoverer ThermoElectron (v: 1.4) was used to analyze acquired LCMS/MS data files.

\subsection{Preparation of monocyte-derived dendritic cells}

Blood from healthy donors was anonymously obtained from Etablissement Français du Sang Ile-de-France (Ivry-sur-Seine, France). Monocytes from peripheral blood mononuclear cells were isolated using anti-CD14 magnetic beads (Miltenyi Biotec, Bergisch Gladbach, Germany) from heparinized buffy coats of healthy donors. Purified monocytes were cultured in RPMI-1640 medium supplemented with $10 \%$ fetal calf serum, L-glutamine and antibiotics in the presence of $500 \mathrm{IU} / 10^{6}$ cells of IL-4 (R\&D Systems, Lille, France) and $1000 \mathrm{IU} /$ $10^{6}$ cells GM-CSF (ImmunoTools, Friesoythe, Germany). After 5 days, the non-adherent immature dendritic cells (DCs)-enriched fraction was harvested and the immature status was confirmed by the expression of surface phenotypic markers (data not shown).

\subsection{Incubation of FVIII with MO-DCs}

For maturation experiments, immature 5-day old MO-DCs $\left(2.5 \times 10^{5}\right.$ cells/well) were incubated in $500 \mu \mathrm{l}$ of X-VIVO ${ }^{15}$ (Lonza) with the different FVIII preparations at 1 or $10 \mathrm{IU} / \mathrm{ml}$ for $48 \mathrm{~h}$. Surface expression of CD80, CD83, CD86, CD40 and HLA-DR was investigated by flow cytometry on 10,000 acquired cells per condition. As a positive control for induction of maturation, we used LPS at $100 \mathrm{ng} / \mathrm{ml}$. Cells incubated alone were used as a negative control.

For FVIII endocytosis experiments, immature MO-DCs ( $4 \times 10^{5}$ cells/well) were incubated for $120 \mathrm{~min}$ with the FVIII at 50 to $400 \mathrm{IU} / \mathrm{ml}$ in $200 \mu \mathrm{l}$ of X-VIVO ${ }^{15}$ at $4{ }^{\circ} \mathrm{C}$ or $37^{\circ} \mathrm{C}$. Intracellular FVIII was recognized after permeabilization with $0.5 \%$ saponin, using the FITClabeled monoclonal antibody (anti-A2 FVIII domain mAb77IP52H7, $10 \mu \mathrm{g} / \mathrm{ml}$, a kind gift from LFB, Les Ulis, France). 10,000 cells were acquired for each condition for flow cytometry analysis. Percentages of cells positive for FVIII were then calculated. Uptake was quantified as the difference in the $\%$ cells at $37^{\circ} \mathrm{C}$ and $4{ }^{\circ} \mathrm{C}$. When indicated, FVIII $(400 \mathrm{IU} / \mathrm{ml}, 215 \mathrm{nM})$ was pre-incubated in $\mathrm{X}-\mathrm{VIVO}^{15}$ with VWF $(87.5 \mathrm{IU} / \mathrm{ml}, 3.6 \mu \mathrm{M})$ for $20 \mathrm{~min}$ at room temperature, prior to incubation with MO-DCs. mAb77IP52H7 does not interfere with the interaction of FVIII with VWF (not shown).

\subsection{FVIII-specific T-cell activation assay}

Five-day old immature MO-DCs derived from monocyte of a healthy 
A

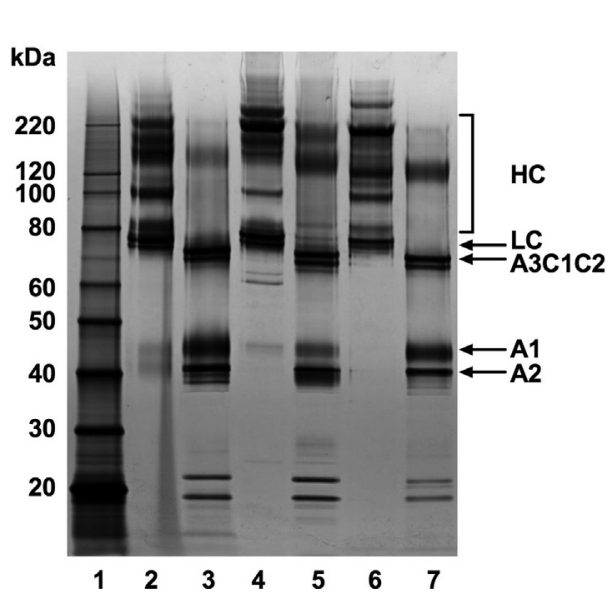

B

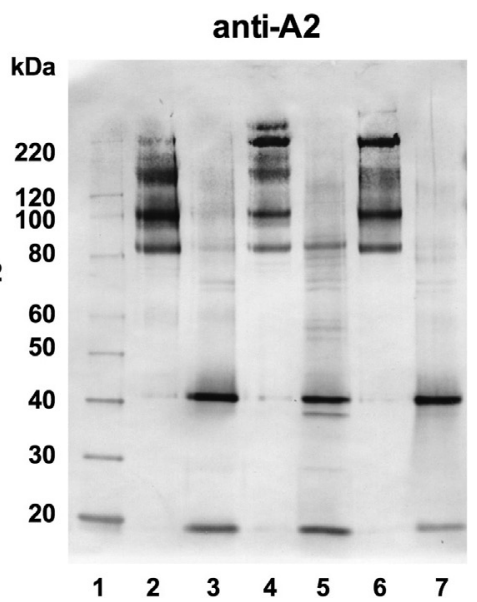

C

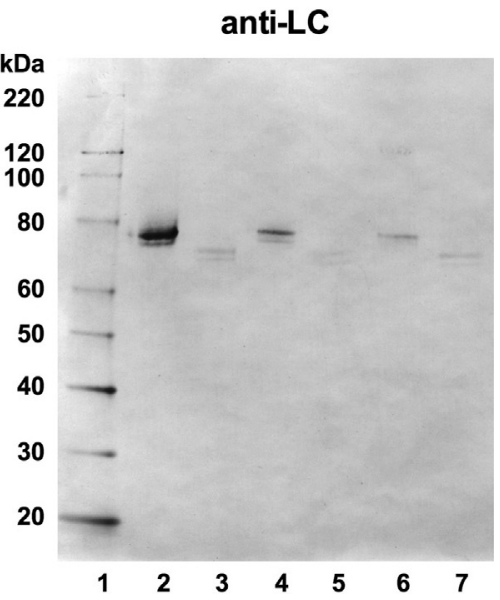

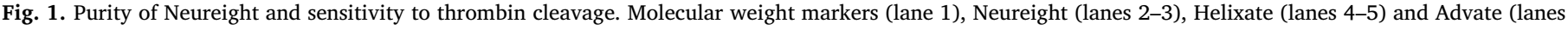

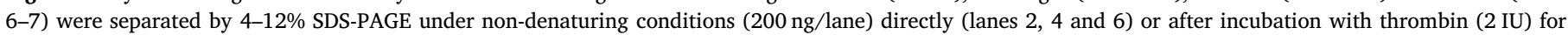

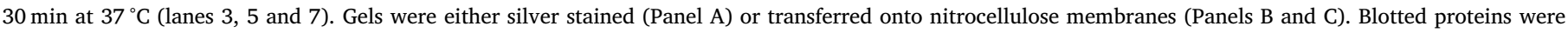

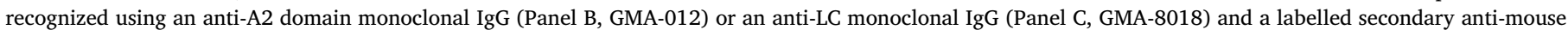

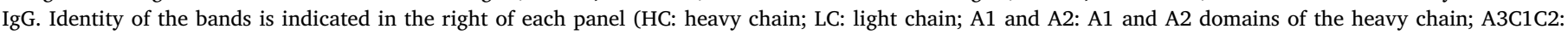
thrombin-cleaved light chain).

donor with the HLA class II DRB1*0101/0301 haplotype, were cultured in RPMI-1640 medium supplemented with 10\% FCS, 2-ME, L-glutamine and antibiotics in 96-round bottom plates, with the 1G8-A2 FVIII-specific HLA-DRB $1 * 0101$-restricted mouse $\mathrm{T}$ cell hybridoma [17] $\left(10^{4}\right.$ DCs: $10^{5} \mathrm{~T}$ cells) in the presence of the different FVIII preparations at 3 , 10 and $30 \mathrm{IU} / \mathrm{ml}$. Twenty four hours later, supernatants were collected and the Il-2 secreted by activated T cells was measured by ELISA.

\subsection{FVIII-deficient mice}

FVIII-deficient mice were 8 to 10 -week old males on a C57BL6 background (a gift from Prof Kazazian, University of Pennsylvania School of Medicine, Philadelphia) and were generated by in-house breeding. Our animal facility uses conventional SPF housing conditions where a maximum of 5 mice are kept in ventilated type IIL cages containing normal bedding, vegetal nests and cardboard tunnels at a temperature of $22^{\circ} \mathrm{C}$ and 12-hour cycles of light/darkness. Mice were maintained on ad libidum normal diet A03 (SAFE, Augy, France) as well as water by automatic distribution. Mice were checked every day. Mice were sacrificed at the end of each experiment following decerebration under anesthesia (2-4\% isofluorane). Mice were handled in agreement with French ethical authorities (Comité National de Réflexion Ethique sur l'Expérimentation Animale, Groupe hospitalier Pitié-Salpêtrière, Paris, France, authorization \# 02058.04).

\subsection{Half-life of FVIII}

FVIII ( $1 \mathrm{IU}$ ) in $100 \mu \mathrm{l}$ was administered intravenously to anesthetized (2-4\% isofluorane) FVIII-deficient mice. The residual FVIII:Ag levels were measured at different time points ( $n \geq 6$ mice per time point and per FVIII product) using a FVIII-specific ELISA assay (Asserachrom, Stago). The data are expressed as the percentage of initial FVIII:Ag level (measured $5 \mathrm{~min}$ after administration) versus time. The half-lives were calculated using Graphpad prism by fitting the data to the two-phase decay model with the plateau constraint set to 0 .

\subsection{Anti-FVIII immune response in FVIII-deficient mice}

Anesthetized FVIII-deficient mice were injected retro-orbital with $1 \mathrm{IU}$ of each FVIII in its respective excipient at day $0,7,14$, and 21. Blood was drawn under anesthesia by retro-orbital bleeding 5 days after the 4th administration of FVIII. Decomplemented plasma $\left(56^{\circ} \mathrm{C}\right.$ for $30 \mathrm{~min}$ ) was kept at $-20^{\circ} \mathrm{C}$ until use. For titration of anti-FVIII IgG, ELISA plates (Nunc) were coated with FVIII $\left(2 \mu \mathrm{g} / \mathrm{mL}\right.$, Recombinate $\left.{ }^{\circledast}\right)$ for $1 \mathrm{~h}$ at $37^{\circ} \mathrm{C}$, and blocked with PBS-1\% BSA. Plasma diluted in PBS$1 \%$ BSA was then incubated for $1 \mathrm{~h}$ at $37^{\circ} \mathrm{C}$. Bound IgG was revealed using a HRP-coupled monoclonal anti-mouse IgG and substrate. The mouse monoclonal anti-FVIII IgG mAb6 (a gift from Prof. J.M. SaintRemy, KUL, Belgium) was used as standard. Results are shown in $\mu \mathrm{g} / \mathrm{ml}$ mAb6-equivalent. For measurement of FVIII inhibitory titers, mouse plasma samples diluted in veronal buffer were incubated with a standard human plasma (Dade-Behring) for $2 \mathrm{~h}$ at $37^{\circ} \mathrm{C}$. The residual procoagulant FVIII activity was measured using a chromogenic assay following the manufacturer's recommendations (Dade-Behring). Bethesda titers, expressed in Bethesda units $(\mathrm{BU}) / \mathrm{mL}$, are defined as the reciprocal of the dilution of plasma that produces $50 \%$ residual FVIII activity.

\section{Results}

\subsection{Production of Neureight}

Neureight was produced using a novel fed-batch disposable fermentation concept in a $400 \mathrm{~L}$ scale using a high producer CHO cell line. Expression of recombinant full-length FVIII reached up to $30 \mathrm{IU} / \mathrm{mL}$ cell culture supernatant. The process was completely serum-free and did not contain animal-derived stabilizer. Purification of Neureight was carried out by applying several chromatographic steps including affinity chromatography. The purity and structural integrity of Neureight were compared to that of commercially available recombinant FVIII products, Helixate and Advate upon separation by SDS-PAGE with or without digestion with thrombin (Fig. 1A). The three recombinant FVIII demonstrated protein bands between 80 and $200 \mathrm{kDa}$, that correspond to the FVIII precursor, as well as the separated light chains (LC) at $80 \mathrm{kDa}$, and the separated heavy (HC), characterized by different molecular weight bands ranging from $90 \mathrm{kDa}$ and higher that correlated to the variable lengths of the B domain, with the A1-A2 domains lacking the B domain as the smallest $\mathrm{HC}$ species at $90 \mathrm{kDa}$. Minor species were also detected between 40 and $50 \mathrm{kDa}$ for Neureight, and to a lesser extent in Helixate and Advate, which can be correlated to the A1 and A2 domains as inferred from the thrombin digested profiles. Digestion of FVIII by thrombin generated the expected 73, 50, and $43 \mathrm{kDa}$ 
Table 1

FVIII:C and FVIII:Ag levels.

\begin{tabular}{lllll}
\hline & FVIII:Ag" (IU/ml) & FVIII:C (IU/ml) & $\begin{array}{l}\text { Proteins } \\
(\mu \mathrm{g} / \mathrm{ml})\end{array}$ & $\begin{array}{l}\text { Specific } \\
\text { activity }^{\dagger} \text { (IU/ } \\
\text { mg) }\end{array}$ \\
\hline Neureight & $4032 \pm 2530$ & $1971 \pm 424$ & $498 \pm 133$ & $4235 \pm 556$ \\
Helixate & $3451 \pm 411$ & $1629 \pm 891$ & $449 \pm 290$ & $3923 \pm 1180$ \\
Advate & $4271 \pm 480$ & $1717 \pm 747$ & $310 \pm 77$ & $6171 \pm 824$ \\
\hline
\end{tabular}

Mean \pm SD of 3 different lots for each product after dialysis against DMEMF12.

${ }^{\circ} \mathrm{FVIII}: \mathrm{C}$ was measured using a chromogenic assay.

* FVIII:Ag was measured using Asserachrom.

$\uparrow$ Protein concentration was measured in a Bradford assay using OVA as a standard.

$\star$ Specific activity reflects the IU of FVIII:C per mg of proteins (Bradford assay).

polypeptide fragments that correspond to the activated LC, and to the A1 and A2 domains of the HC, respectively. Thrombin digestion of Neureight confirmed the absence of contaminating protein in the preparation. Indeed, all the protein bands on the gel were sensitive to thrombin cleavage and demonstrated changes in migration profile, thus showing that they belong to FVIII.

The identity of the three products was further confirmed by Western blotting using monoclonal anti-A2 and anti-LC IgG (Fig. 1B and 1C, respectively). After dialysis against DMEM-F12, specific activities were $4235 \pm 556,3923 \pm 1180$ and $6171 \pm 824 \mathrm{IU} / \mathrm{mg}$ for Neureight, Helixate and Advate, respectively (Table 1, means \pm SD of 3 different lots), further substantiating the proper structure and function of Neureight.

\subsection{Glycan profiling}

$\mathrm{N}$-glycan profiles of Neureight revealed both high mannose type glycan forms (Man)5(GlcNAc)2 to (Man)9(GlcNAc)2 and complex type glycans (Table 2). The majority of complex structures were fucosylated and sialylated. The level of sialylated $\mathrm{N}$-glycans was determined with a percentage relative abundance of $59 \%$ for Neureight, as compared to $86 \%$ for Advate. High mannose type glycans were determined with a percentage relative abundance of $11 \%$ in the case of Neureight, compared to $4 \%$ in that of Advate. Importantly, the $\mathrm{N}$-glycan profiles did not show the presence of the antigenic epitope Neu5Gc or of the nonhuman antigenic epitope galactose- $\alpha 1,3$-galactose (Gal-alpha-Gal) on $\mathrm{N}$-glycans of the proteins. Neu5Gc was also undetectable in O-glycan profiling.
Table 3

Identification and assignment of sulfation sites.

\begin{tabular}{|c|c|c|c|c|c|}
\hline \multirow{2}{*}{$\begin{array}{l}\text { Sulfation } \\
\text { (Y) }\end{array}$} & \multirow{2}{*}{$\begin{array}{l}\text { Peptide } \\
\text { position }\end{array}$} & \multirow{2}{*}{$\begin{array}{l}\text { Number of } \\
\text { sulfates }\end{array}$} & \multirow{2}{*}{$\begin{array}{l}\text { Theoretical } \\
\text { average mass } \\
\text { (Da) }\end{array}$} & Neureight & Advate \\
\hline & & & & \multicolumn{2}{|c|}{$\begin{array}{l}\text { Measured average mass } \\
\text { (Da) }\end{array}$} \\
\hline Y718, & $714-733^{*}$ & 1 & 2425.6 & 2424.9 & 2425.2 \\
\hline $\begin{array}{l}\text { Y719, } \\
\text { Y723 }\end{array}$ & & 2 & 2505.6 & 2505.7 & 2505.8 \\
\hline Y1680 & 1674-1689 & 1 & 2079.1 & 2079.1 & 2079.1 \\
\hline
\end{tabular}

* The tri-sulfated peptide was not detected as it is too unstable to be seen in the negative MALDI mode, but is likely to be present. The fact that mono-and di-sulfated peptides are also visible in the linear positive mode is a good indication that these ions are generated by spontaneous fragmentation of the trisulfated molecule.

\subsection{Identification and assignment of sulfation sites, glycosylation sites and glycopeptides}

The occupation sites and the type of glycan structures found for each of the 16 identified N-glycosylation sites were similar between Neureight and Advate (Table 2). For both molecules, the N41 glycosylation site was mainly occupied with complex bi-antennary glycans, mostly core-fucosylated and asialylated structures, the N943 and N2118 glycosylation sites both contained only high mannose type glycans, the N239 and N1066 sites presented with high mannose types and non-sialylated complex glycans, and the N1412 site was occupied by sialylated bi-antennary structures. For both Neureight and Advate, the N1255 glycosylation site was occupied only by high mannose-type glycans, while the N1259 glycosylation site was occupied by a variety of bi- and tri-antennary complex glycans with and without sialic acid (not shown). Tyrosine (Y) sulfation was identical between Advate and Neureight in terms of determined sites of tyrosine sulfation: the 714-733 peptide harboring the three tyrosine sulfation sites Y718, 719 and 723 was sulfated (Table 3). Both molecules showed sulfation of Y1680 (see Table 3), which is critical for the FVIII-VWF interaction.

\subsection{Induction of maturation of monocyte-derived dendritic cells (MO-DCs)}

In order to assess the potential immunogenicity of Neureight, we compared the capacity of the three FVIII products to induce the maturation of human immature MO-DCs. Incubation of 5-day old MO-DCs with LPS, used as a positive control, resulted in the overexpression of CD80, CD83, CD40 and HLA-DR (Fig. 2). In contrast, and as described previously [18], Advate and Helixate failed to induce the maturation of MO-DCs. Likewise, Neureight did not alter the immature profile of MODCs, irrespective of the FVIII concentration used in the assay. The results also reflect the lack of contamination of Neureight with endotoxins.

Table 2

Identification and assignment of glycosylation sites and glycopeptides.

\begin{tabular}{|c|c|c|c|c|c|}
\hline \multirow[b]{2}{*}{ Site $(\mathrm{N})$} & \multirow[b]{2}{*}{ Isolated peptide } & \multicolumn{2}{|l|}{ Neureight } & \multicolumn{2}{|l|}{ Advate } \\
\hline & & $\begin{array}{l}\text { Mass range of detected } \\
\text { glycopeptides (Da) }\end{array}$ & Description & $\begin{array}{l}\text { Mass range of detected } \\
\text { glycopeptides (Da) }\end{array}$ & Description \\
\hline N41 & $37-47$ & $2588.79-3349.53$ & $\begin{array}{l}\text { complex bi-antennary glycans mostly } \\
\text { core-fucosylated and asialylated } \\
\text { structures }\end{array}$ & $2589.49-3349.63$ & $\begin{array}{l}\text { complex bi-antennary glycans mostly } \\
\text { core-fucosylated and asialylated } \\
\text { structures }\end{array}$ \\
\hline N943 & $926-946$ & $3851.20-4015.48$ & $\begin{array}{l}\text { high mannose type structures (Man } \\
8-9 \text { ) }\end{array}$ & $3850.76-4013.48$ & high mannose type structures (Man 8-9) \\
\hline N239 & $231-240$ & $2408.80-3058.59$ & high mannose type and non-sialylated & $2409.13-3058.97$ & high mannose type and non-sialylated \\
\hline N1066 & $1061-1067$ & $2289.88-2815.15$ & complex structures & $2288.14-2815.46$ & complex structures \\
\hline N1412 & $1407-1422$ & 3867.55 & Sialylated biantennary structure & 3866.54 & Sialylated biantennary structure \\
\hline N2118 & $2117-2136$ & $3411.34-3897.38$ & $\begin{array}{l}\text { high mannose type structures (Man } \\
6-9 \text { ) }\end{array}$ & $3412.72-3898.33$ & high mannose type structures (Man 6-9) \\
\hline
\end{tabular}



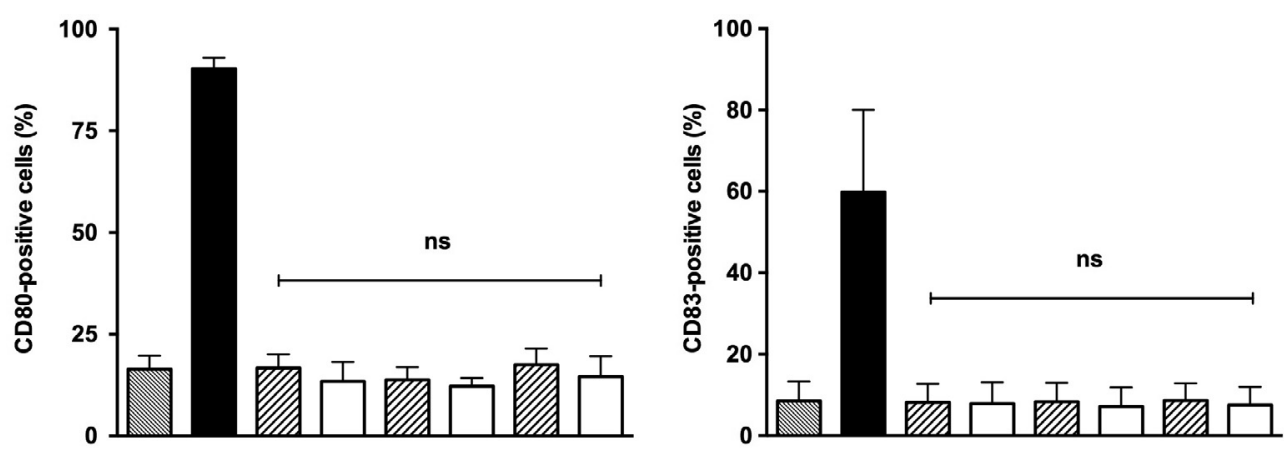

Fig. 2. Induction of maturation of MO-DCs by different recombinant FVIII products. Neureight, Advate and Helixate were incubated at 1 or $10 \mathrm{IU} / \mathrm{ml}$ (FVIII:Ag) with 5day old immature human MO-DCs for $48 \mathrm{~h}$. The expression of CD80, CD83, CD86, CD40 and HLA-DR was measured by flow cytometry and is expressed as percent of positive cells (CD80, CD83) and mean fluorescence intensity (MFI, CD40, HLA-DR). LPS was used as a positive control for the induction of MO-DC maturation. The results represent means and SEM of 3 independent experiments. Differences were not statistically significant (ns) as assessed using a two-
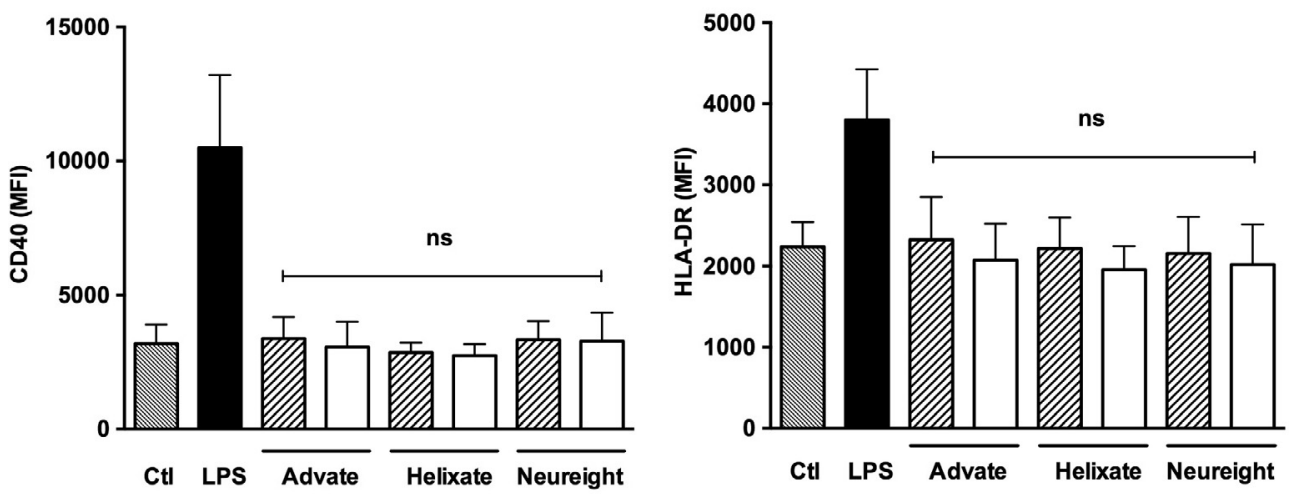
tailed non-parametric Mann-Whitney test.

\section{$1 \mathrm{IU} / \mathrm{ml}$ FVIII:Ag}

\section{$10 \mathrm{IU} / \mathrm{mI} \mathrm{FVIII:Ag}$}

\subsection{Endocytosis of Neureight by MO-DCs}

The endocytosis of Neureight, Advate and Helixate by 5-day old immature MO-DCs was measured as a function of the concentration of FVIII. The 3 FVIII products were endocytosed in a dose-dependent manner (Fig. 3A). VWF has been reported to inhibit the endocytosis of FVIII by dendritic cells $[19,20]$. We thus compared the protective effect of VWF on FVIII endocytosis in our assay. The three FVIII products $(400 \mathrm{IU} / \mathrm{ml})$ were pre-incubated alone or with a 30 -fold molar excess of VWF. FVIII was endocytosed by $37 \pm 10,40 \pm 4$ and $27 \pm 4 \%$ of the cells in the case of Advate, Helixate, and Neureight, respectively (Fig. 3B). When the FVIII products were pre-incubated with VWF, percentages of FVIII-positive cells were reduced to $8 \pm 2,12 \pm 2$ and $14 \pm 4 \%$, respectively. VWF thus reduced the endocytosis of FVIII by $70 \pm 15,68 \pm 9$ or $49 \pm 15 \%$ in the case of Advate, Helixate, Neureight, respectively (Fig. 3C). Differences between products were not statistically significant. Normal binding of Neureight to VWF was further substantiated by the observation of unaltered circulating halflife in FVIII-deficient mice, as compared to Advate (Fig. 4A).

\subsection{Activation of FVIII-specific CD4+ T cells}

To test whether the endocytosis of Neureight by MO-DCs leads to the activation of $\mathrm{T}$ cells in vitro, we took advantage of a FVIII-specific mouse T-cell hybridoma that is restricted to the human HLADRB1*0101 allele, and can be activated by human MO-DCs with the HLA-DRB1*0101 haplotype or by splenocytes from HLA-DRB1*0101transgenic SureL1 mice [17]. The three different FVIII products were presented by human MO-DCs to T cells in a dose-dependent manner and to similar levels (Fig. 3D), suggesting that Neureight is endocytosed to a similar extent as Helixate and Advate by antigen-presenting cells, at FVIII concentrations below $100 \mathrm{IU} / \mathrm{ml}$.

\subsection{Immunogenicity of Neureight in FVIII-deficient mice}

The three recombinant FVIII products were administered intravenously once a week for 4 weeks to FVIII-deficient mice at a quantity close to replacement doses in the human (50 IU $/ \mathrm{kg}$ ). After 4 administrations of FVIII, there was no statistical difference between the levels of anti-FVIII IgG induced by the three recombinant FVIII products $(1816.0 \pm 519.9, \quad 1896.0 \pm 478.9$ and $680.7 \pm 329.9 \mu \mathrm{g} / \mathrm{ml}$ for Advate, Helixate and Neureight, respectively, Fig. 4B). Levels of FVIII inhibitors, measured by the Bethesda assay (Fig. 4C), were statistically different between mice treated with Advate $(123.3 \pm 50.4 \mathrm{BU} / \mathrm{ml}$, mean \pm SEM) and mice treated with Neureight $(15.7 \pm 10.2 \mathrm{BU} / \mathrm{ml}$, $\mathrm{P}<.01)$. There was however no significant difference between Helixate $(120.2 \pm 43.6 \mathrm{BU} / \mathrm{ml})$ and Neureight.

\section{Discussion}

The objective of the present work was to validate the structural and functional integrity and lack of increased immunogenicity of Neureight, a recombinant full-length FVIII produced in CHO cells using a novel fed-batch fermentation mode based on a disposable concept. Neureight demonstrated a migration profile and sensitivity to digestion by thrombin, similar to that of Advate and Kogenate, two commercially available full-length FVIII produced using the classical perfusion technology. Importantly, thrombin digestion revealed the absence of contaminating non-cleavable protein bands in the three preparations, indicating similar degrees of purity of the end products. Importantly, the cell culture supernatant was harvested at high cell viabilities (>90\%) which may contribute to the quality of Neureight by limiting the accumulation of harmful/toxic metabolic by-products and keeping low levels of apoptotic cells. The purity and functional integrity of Neureight was further confirmed by the determination of the specific 

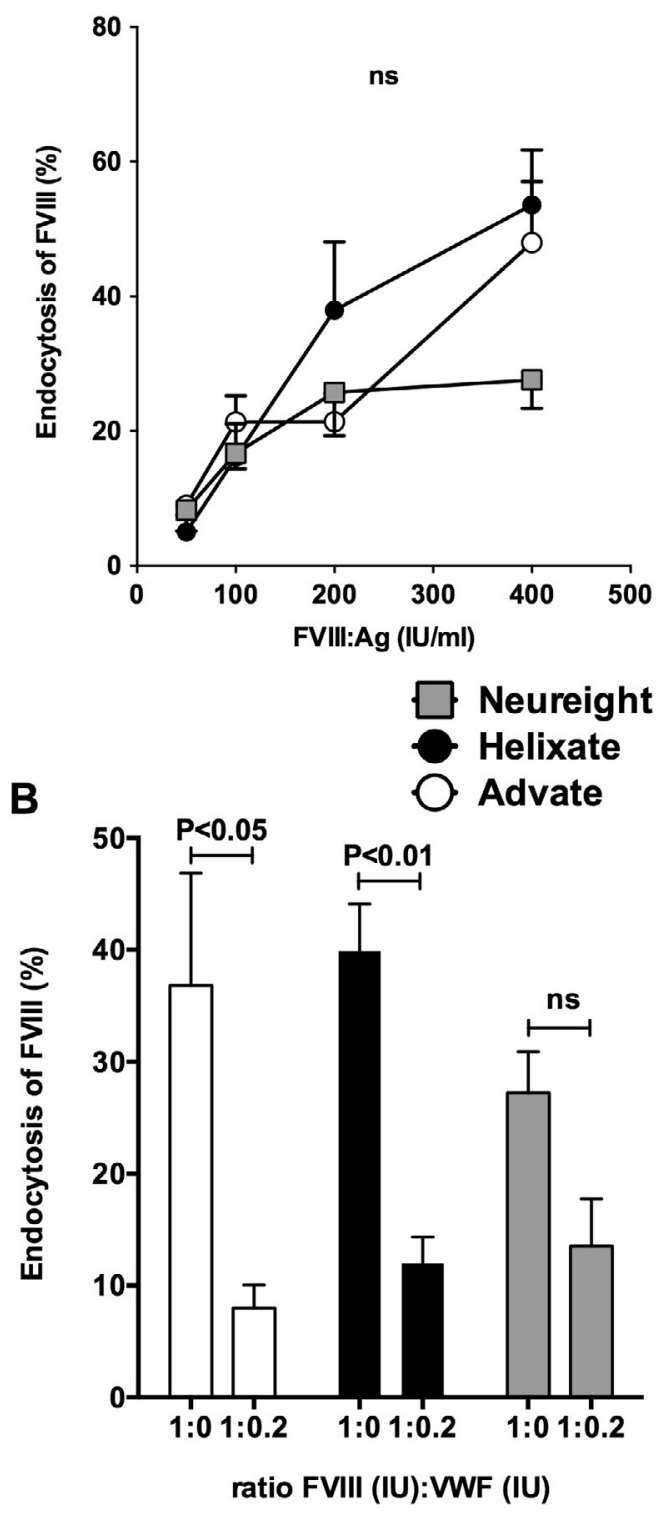

activities that were in the range reported for commercially available products, i.e., $4000-10,000 \mathrm{IU} / \mathrm{mg}$ for Advate and $2600-6800 \mathrm{IU} / \mathrm{mg}$ for Helixate [21].

Glycosylation is the most common post-translational modification observed in extracellular and integral membrane proteins. It impacts proper folding and efficient secretion of many extracellular proteins. Glycosylation also plays a significant role in determining the plasma half-life and biologic activity of several proteins. FVIII is extensively $\mathrm{N}$ glycosylated, especially within the B-domain, with a variety of complex-, hybrid- and high mannose-type glycan structures [22]. As anticipated, the comparison of Neureight and Advate, that are both produced in $\mathrm{CHO}$ cells, by mass-spectrometry confirmed the heavily glycosylated profile of the two proteins with complex, hybrid- and high mannose-type glycosylations. The identical glycan structures were present at the same sites on both molecules, and there was a complete absence of the antigenic carbohydrate epitopes $\alpha$-Gal and Neu5Gc [23]. Tyrosine sulfation is another post-translational modification that takes place in the trans-Golgi apparatus. Tyrosine sulfation of FVIII is required for full pro-coagulant activity as well as for optimal binding to VWF. Our study confirms the mono and di-sulfation of Neureight and Advate at the 714-733 peptide, while the tri-sulfated peptide was too
Fig. 3. Endocytosis and presentation of recombinant FVIII. Panel A. Immature five-day-old MO-DCs were incubated in X-VIVO ${ }^{15}$ medium containing 50 to $400 \mathrm{IU} / \mathrm{ml}$ FVIII (FVIII:Ag) for $120 \mathrm{~min}$ at $37^{\circ} \mathrm{C}$ or at $4^{\circ} \mathrm{C}$. The percent of cells having endocytosed FVIII was measured by subtracting the fluorescence measured at $4^{\circ} \mathrm{C}$ from that measured at $37^{\circ} \mathrm{C}$ minus. Results depict percent of positive cells. Error bars indicate SEM for 4 independent experiments with MODCs from 4 different healthy donors. ns: not significant as assessed using a two-way ANOVA. Panels B and C. FVIII (400 IU/ml FVIII:Ag) was pre-incubated for $20 \mathrm{~min}$ alone or in the presence of $87.5 \mathrm{IU} / \mathrm{ml}$ plasma-derived $\mathrm{VWF}$ at room temperature. Mixtures were then incubated at $4{ }^{\circ} \mathrm{C}$ or $37^{\circ} \mathrm{C}$ in X-VIVO ${ }^{15}$ medium containing $400 \mathrm{IU} / \mathrm{ml}$ FVIII:Ag. ns: not significant as assessed by the non-parametric Kruskal-Wallis test. In panel C, percent inhibition in the presence of VWF was calculated as the $\%$ FVIII-positive cells measured in the presence of VWF versus that measured in the absence of VWF. Results are mean \pm SEM of 3 independent experiments. Panel D. Five-day old immature MO-DCs from healthy donors with the HLA class II DRB1*0101/0301 haplotypes, were cultured with the 1G8-A2 FVIII specific HLA-DRB1*0101restricted mouse T-cell hybridoma in the presence of FVIII (1, 3, 10 and $30 \mathrm{IU} / \mathrm{ml}$ FVIII:Ag). Supernatant was collected after $24 \mathrm{~h}$ and Il-2 was measured in supernatant. Representative of three experiments. Data were normalized according to the IL-2 production measured for Helixate at $30 \mathrm{IU} / \mathrm{ml} \mathrm{FVIII:Ag} \mathrm{and} \mathrm{are} \mathrm{depicted} \mathrm{as} \mathrm{\%} \mathrm{acti-}$ vation of the T-cell hybridoma. ns: not significant as assessed using a two-way ANOVA. unstable to be seen in the negative MALDI mode for both products. More importantly for proper binding to VWF, our study also confirms sulfation at Y1680.

The immunogenicity of a protein may result from different properties [24], including the capacity to be endocytosed by antigen-presenting cells, the capacity to provide maturation signals that trigger the maturation of the antigen-presenting cells, the capacity to intracellularly bind to MHC class II and be presented to T cells, as well as the presence in the organism of $\mathrm{CD} 4+\mathrm{T}$ cells that are specific for the therapeutic protein-derived peptides and that are able to be activated (i.e., absence of active tolerance). Both full-length and B domain-deleted therapeutic FVIII products have been shown to be endocytosed by human MO-DCs. Although controversial, the endocytosis of FVIII implicates mannose-ending sugars and charged amino-acid residues in the C1 and C2 domains of FVIII [25-27]. Studies have ruled out a role for LRP and related receptors in the endocytic process by MO-DCs and implicated mannose-sensitive receptors such as CD206 [28,29]. In our hands, Neureight was endocytosed with a dose-dependency identical to that of Advate and Helixate, suggesting that the moieties implicated in FVIII internalization are identical irrespective of the method used to produce FVIII (fed-batch or perfusion approaches). Besides, the 
A

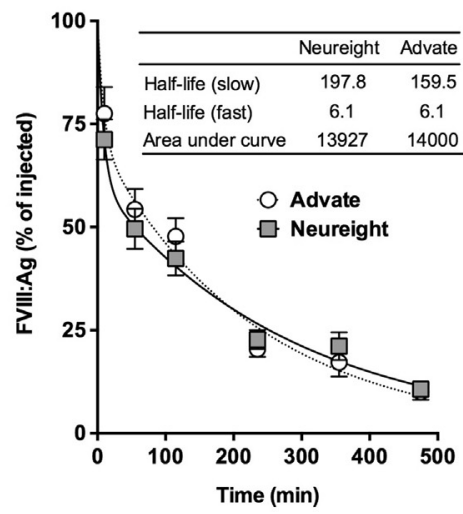

B

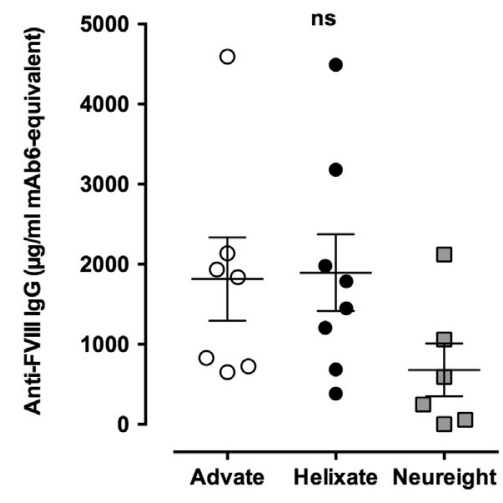

C

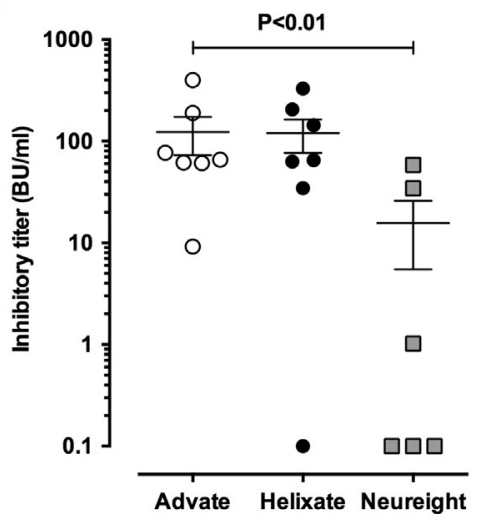

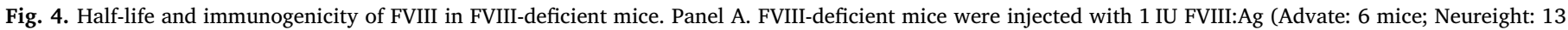

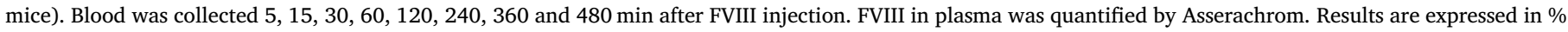

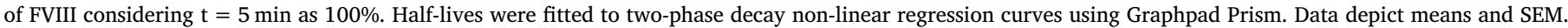

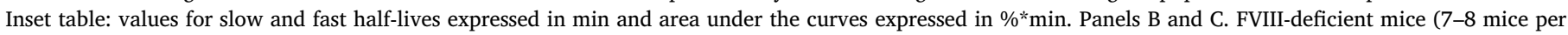

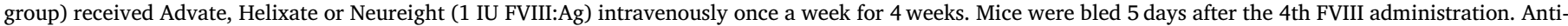

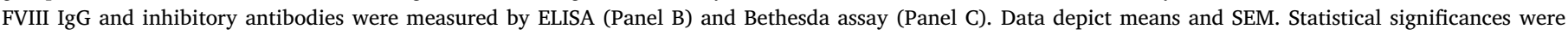
assessed with the non-parametric double-sided Mann-Whitney test (ns: not significant).

internalized Neureight was presented to a CD4 + T-cell hybridoma to a similar level as the two therapeutic proteins and both by mouse (not shown) and human antigen-presenting cells. The latter set of data indicates that the intracellular processing of Neureight does not differ from that of Advate and Helixate.

Previous work had documented that FVIII does not alter the maturation state of MO-DCs [18]. Indeed, incubation of Advate and Helixate with MO-DCs had no effect on the maturation state of the cells as assessed by the expression levels of CD80, CD83, CD40 and HLA-DR. Likewise, Neureight did not impart on the maturation profile of FVIII, suggesting that its binding to the surface of MO-DCs is identical to that of the other recombinant FVIII, and that it does not contain significant levels of endotoxins.

Interestingly, the levels of anti-FVIII IgG induced by Neureight in FVIII-deficient mice were identical to those induced by Advate and Helixate. In contrast, the inhibitory titers developed by the mice following administration of Neureight were significantly lower than that generated by the other FVIII proteins. An important difference between the in vivo model of severe hemophilia A and the in vitro predictive tests for FVIII immunogenicity used in the present work, is the presence or absence of VWF, respectively. VWF is a chaperon molecule that protects FVIII in the circulation from degradation by circulating enzymes, and transports FVIII to the site of bleeding. Controversial results suggest that VWF-containing FVIII may be less immunogenic in hemophilia A patients $[2,30,31]$ and that VWF reduces the immunogenicity of FVIII in FVIII-deficient mice [32-34]. Here, we confirmed that VWF reduces the internalization of Helixate and Advate by MO-DCs in vitro [19]. Similarly, the endocytosis of Neureight was reduced, although without reaching statistical significance, in the presence of a physiological molar excess of VWF. The lack of statistical significance may be due to the somewhat lower amount of Neureight that is endocytosed, as compared to Advate and Helixate, when FVIII concentrations $>100$ $\mathrm{IU} / \mathrm{ml}$ are used in the assay. In addition, the half-life of Advate and Neureight were identical in FVIII-deficient mice, thus confirming the structural integrity of Neureight as well as its conserved ability to bind VWF. Taken together, our data predict that the immunogenicity of Neureight, at least as assessed using in vitro immunological assays or using the experimental model of severe hemophilia A, is similar to that of Advate and Helixate.

In conclusion, the production of full-length FVIII in a fed-batch fermentation mode generates a product that presents similar biochemical and functional properties as products developed using the classical perfusion technology. Further, the immunogenicity profile of the fed-batch fermentation product is not different from that of commercially available full-length products. Adoption of the fed-batch fermentation strategy should allow a substantial decrease in production costs in the range of $20-40 \%$ and permit the delivery of an efficient and safe recombinant FVIII product to developing countries.

\section{Acknowledgements}

This work was supported by INSERM, Centre National de la Recherche Scientifique, Université Pierre et Marie Curie Paris 6, and by a grant from Minapharm Pharmaceuticals S.A.E (Cairo, Egypt). Glycosylation and sulfation studies were performed by Proteodynamics SARL, France.

\section{References}

[1] P.M. Mannucci, E.G. Tuddenham, The hemophilias-from royal genes to gene therapy, N. Engl. J. Med. 344 (2001) 1773-1779.

[2] F. Peyvandi, P.M. Mannucci, I. Garagiola, A. El-Beshlawy, M. Elalfy, V. Ramanan, P. Eshghi, S. Hanagavadi, R. Varadarajan, M. Karimi, M.V. Manglani, C. Ross, G. Young, T. Seth, S. Apte, D.M. Nayak, E. Santagostino, M.E. Mancuso, A.C. Sandoval Gonzalez, J.N. Mahlangu, S. Bonanad Boix, M. Cerqueira, N.P. Ewing, C. Male, T. Owaidah, V. Soto Arellano, N.L. Kobrinsky, S. Majumdar, R. Perez Garrido, A. Sachdeva, M. Simpson, M. Thomas, E. Zanon, B. Antmen, K. Kavakli, M.J. Manco-Johnson, M. Martinez, E. Marzouka, M.G. Mazzucconi, D. Neme, A. Palomo Bravo, R. Paredes Aguilera, A. Prezotti, K. Schmitt, B.M. Wicklund, B. Zulfikar, F.R. Rosendaal, A randomized trial of factor VIII and neutralizing antibodies in hemophilia A, N. Engl. J. Med. 374 (2016) 2054-2064.

[3] A. Coppola, A. D'Ausilio, A. Aiello, S. Amoresano, M. Toumi, P. Mathew, A. Tagliaferri, G. Potter Study, Cost-effectiveness analysis of late prophylaxis vs. ondemand treatment for severe haemophilia A in Italy, Haemophilia (2017).

[4] H.T. Spencer, G. Denning, R.E. Gautney, B. Dropulic, A.J. Roy, L. Baranyi, B. Gangadharan, E.T. Parker, P. Lollar, C.B. Doering, Lentiviral vector platform for production of bioengineered recombinant coagulation factor VIII, Mol. Ther. 19 (2011) 302-309.

[5] D.M. Fantacini, A.M. Fontes, M.S. de Abreu Neto, D.T. Covas, V. Picanco-Castro, The F309S mutation increases factor VIII secretion in human cell line, Rev. Bras. Hematol. Hemoter. 38 (2016) 135-140.

[6] B.G.D. Boedeker, Recombinant factor VIII (Kogenate $\left.{ }^{\oplus}\right)$ for the treatment of hemophilia A: the first and only world-wide licensed recombinant protein produced in high-throughput perfusion culture, in: J. Knäblein (Ed.), Modern Biopharmaceuticals: Recent Success Stories, Wiley-VCH Verlag GmbH \& Co. KGaA, Weinheim, Germany, 2013, pp. 429-443.

[7] B.G. Boedeker, Production processes of licensed recombinant factor VIII preparations, Semin. Thromb. Hemost. 27 (2001) 385-394.

[8] N. Riedel, F. Dorner, A new technology standard for safety and efficacy in factor VIII replacement therapy: designing an advanced category rFVIII concentrate, in: J. Knäblein (Ed.), Modern Biopharmaceuticals: Design, Wiley-VCH Verlag GmbH, Weinheim, Germany, Development and Optimization, 2008. 
[9] J. Pollock, S.V. Ho, S.S. Farid, Fed-batch and perfusion culture processes: economic, environmental, and operational feasibility under uncertainty, Biotechnol. Bioeng. 110 (2013) 206-219.

[10] S.C. Kim, S. An, H.K. Kim, B.S. Park, K.H. Na, B.G. Kim, Effect of transmembrane pressure on Factor VIII yield in ATF perfusion culture for the production of recombinant human Factor VIII co-expressed with von Willebrand factor, Cytotechnology 68 (2016) 1687-1696.

[11] F.M. Wurm, Production of recombinant protein therapeutics in cultivated mammalian cells, Nat. Biotechnol. 22 (2004) 1393-1398.

[12] S. Soukharev, D. Hammond, N.M. Ananyeva, J.A. Anderson, C.A. Hauser, S. Pipe, E.L. Saenko, Expression of factor VIII in recombinant and transgenic systems, Blood Cells Mol. Dis. 28 (2002) 234-248.

[13] W. Whitford, Fed-batch mammalian cell culture, BioProcess Int. (2006) 30-40.

[14] A.A. Shukla, U. Gottschalk, Single-use disposable technologies for biopharmaceutical manufacturing, Trends Biotechnol. 31 (2013) 147-154.

[15] H.L. Levine, Single-Use Technology and Modular Construction, BioProcess Int. 11 (2013) 40-45.

[16] U. Noack, Single-Use Stirred Tank Reactor BIOSTAT CultiBag STR: Characterization and Applications, Single-Use Technology in Biopharmaceutical Manufacture, John Wiley \& Sons, Inc, 2010, pp. 225-240.

[17] S. Delignat, Y. Repesse, L. Gilardin, J.D. Dimitrov, Y.C. Lone, S.V. Kaveri, S. LacroixDesmazes, Predictive immunogenicity of Refacto AF, Haemophilia 20 (2014) 486-492.

[18] K. Pfistershammer, J. Stockl, J. Siekmann, P.L. Turecek, H.P. Schwarz, B.M. Reipert, Recombinant factor VIII and factor VIII-von Willebrand factor complex do not present danger signals for human dendritic cells, Thromb. Haemost. 96 (2006) 309-316.

[19] S. Dasgupta, Y. Repesse, J. Bayry, A.M. Navarrete, B. Wootla, S. Delignat, T. Irinopoulou, C. Kamate, J.M. Saint-Remy, M. Jacquemin, P.J. Lenting, A. BorelDerlon, S.V. Kaveri, S. Lacroix-Desmazes, VWF protects FVIII from endocytosis by dendritic cells and subsequent presentation to immune effectors, Blood 109 (2007) 610-612.

[20] E. Herczenik, S.D. van Haren, A. Wroblewska, P. Kaijen, M. van den Biggelaar, A.B. Meijer, L. Martinez-Pomares, A. ten Brinke, J. Voorberg, Uptake of blood coagulation factor VIII by dendritic cells is mediated via its C1 domain, J. Allergy Clin. Immunol. 129 (2012) 501-509 509 e501-505.

[21] M. Brooker, Registry of Clotting Factor Concentrates, Facts and Figures, World Federation of Hemophilia, Montreal, Quebec, Canada, 2012.

[22] K. Hansson, J. Stenflo, Post-translational modifications in proteins involved in blood coagulation, J. Thromb. Haemost. 3 (2005) 2633-2648.

[23] C. Kannicht, M. Ramstrom, G. Kohla, M. Tiemeyer, E. Casademunt, O. Walter, H. Sandberg, Characterisation of the post-translational modifications of a novel, human cell line-derived recombinant human factor VIII, Thromb. Res. 131 (2013) $78-88$

[24] S. Lacroix-Desmazes, A.M. Navarrete, S. Andre, J. Bayry, S.V. Kaveri, S. Dasgupta,
Dynamics of factor VIII interactions determine its immunologic fate in hemophilia A, Blood 112 (2008) 240-249.

[25] S. Dasgupta, A.M. Navarrete, J. Bayry, S. Delignat, B. Wootla, S. Andre, O. Christophe, M. Nascimbeni, M. Jacquemin, L. Martinez-Pomares, T.B. Geijtenbeek, A. Moris, J.M. Saint-Remy, M.D. Kazatchkine, S.V. Kaveri, S. Lacroix-Desmazes, A role for exposed mannosylations in presentation of human therapeutic self-proteins to CD4 + T lymphocytes, Proc. Natl. Acad. Sci. U.S.A. 104 (2007) 8965-8970.

[26] A. Wroblewska, S.D. van Haren, E. Herczenik, P. Kaijen, A. Ruminska, S.Y. Jin, X.L. Zheng, M. van den Biggelaar, A. Ten Brinke, A.B. Meijer, J. Voorberg, Modification of an exposed loop in the $\mathrm{C} 1$ domain reduces immune responses to factor VIII in hemophilia A mice, Blood 119 (2012) 5294-5300.

[27] B. Gangadharan, M. Ing, S. Delignat, I. Peyron, M. Teyssandier, S.V. Kaveri, S. Lacroix-Desmazes, The C1 and C2 domains of blood coagulation factor VIII mediate its endocytosis by dendritic cells, Haematologica 102 (2017) 271-281.

[28] S. Dasoupta, A.M. Navarrete, S. Andre, B. Wootla, S. Delignat, Y. Repesse, J. Bayry, A. Nicoletti, E.L. Saenko, R. d'Oiron, M. Jacquemin, J.M. Saint-Remy, S.V. Kaveri, S. Lacroix-Desmazes, Factor VIII bypasses CD91/LRP for endocytosis by dendritic cells leading to T-cell activation, Haematologica 93 (2008) 83-89.

[29] A.M. Navarrete, S. Dasgupta, M. Teyssandier, Y. Repesse, S. Delignat, S. Andre, J. Bayry, S.V. Kaveri, S. Lacroix-Desmazes, Endocytic receptor for pro-coagulant factor VIII: relevance to inhibitor formation, Thromb. Haemost. 104 (2010) 1093-1098.

[30] T. Calvez, Y. Laurian, J. Goudemand, Inhibitor incidence with recombinant vs. plasma-derived FVIII in previously untreated patients with severe hemophilia A: homogeneous results from four published observational studies, J. Thrombosis Haemostasis: JTH 6 (2008) 390-392.

[31] S.C. Gouw, J.G. van der Bom, R. Ljung, C. Escuriola, A.R. Cid, S. ClaeyssensDonadel, C. van Geet, G. Kenet, A. Makipernaa, A.C. Molinari, W. Muntean, R. Kobelt, G. Rivard, E. Santagostino, A. Thomas, H.M. van den Berg, Factor VIII products and inhibitor development in severe hemophilia A, New Engl. J. Med. 368 (2013) 231-239.

[32] M. Behrmann, J. Pasi, J.M. Saint-Remy, R. Kotitschke, M. Kloft, Von Willebrand factor modulates factor VIII immunogenicity: comparative study of different facto VIII concentrates in a haemophilia A mouse model, Thromb. Haemost. 88 (2002) 221-229.

[33] S. Delignat, S. Dasgupta, S. Andre, A.M. Navarrete, S.V. Kaveri, J. Bayry, M.H. Andre, S. Chtourou, Z. Tellier, S. Lacroix-Desmazes, Comparison of the immunogenicity of different therapeutic preparations of human factor VIII in the murine model of hemophilia A, Haematologica 92 (2007) 1423-1426.

[34] M. Qadura, B. Waters, E. Burnett, R. Chegeni, S. Bradshaw, C. Hough, M. Othman, D. Lillicrap, Recombinant and plasma-derived factor VIII products induce distinct splenic cytokine microenvironments in hemophilia A mice, Blood 114 (2009) $871-880$. 